\title{
Plasma Concentrations of Hormones and Metabolic Substrates in Growing Pigs after Bovine Growth Hormone Injections under Various Nutritional Conditions
}

\author{
AKIHITo OZAWA, KoIchi HODATE*, AND Tetsu JOHKE \\ National Institute of Animal Industry, Ibaraki 305, and \\ *Tohoku National Agricultural Experiment Station, Iwate 020-01, Japan
}

\begin{abstract}
The effects of GH injections on the concentrations of plasma hormones and metabolic substrates in pigs were studied under various nutritional conditions. In experiment 1 , four pigs (Large white, barrows, 108 days old) were maintained at three feeding levels: (1) high level $(8,501 \pm 46 \mathrm{kcal} /$ day), (2) maintenance level (2,104 $\pm 44 \mathrm{kcal} /$ day), and (3) fasting (last meal was on day -2$)$. The bovine GH $(100 \mu \mathrm{g} / \mathrm{kg} \mathrm{BW})$ was subcutaneously injected on experiment days 0,1 , and 2 . In experiment 2 , four pigs (Landrase, barrows, 120 days old) were maintained at the high feeding level and the bovine $\mathrm{GH}$ $(100 \mu \mathrm{g} / \mathrm{kg} \mathrm{BW})$ was injected 2, 26, and $50 \mathrm{~h}$ after the last meal. The plasma hormone and metabolic substrate concentrations were measured. In experiment 1 , the plasma IGF-I concentrations increased on days 1-4 in the high feeding level and maintenance fed pigs, but did not increase in the fasting pigs. The plasma glucose concentrations increased after the GH injection in the high feeding level and maintenance fed animals. The plasma NEFA concentrations increased after the GH injection in the maintenance fed and fasting animals. In experiment 2, the plasma IGF-I gradually decreased after the last meal. The GH injection administered 26 or $50 \mathrm{~h}$ after the last meal still produced an increase in the plasma IGF-I levels. These data clearly show that the effect of GH was modified depending on the nutritional condition of the pigs.
\end{abstract}

Key words: GH, Nutrition, IGF-I, Metabolites, Pig

(Endocrine Journal 43: 357-362, 1996)

THE DAILY administration of GH stimulates growth in normal pigs [1-3]. The $36 \%$ faster growth rate and $28 \%$ lower feed: gain ratio were reported during the treatment period from $30 \mathrm{~kg}$ to $60 \mathrm{~kg}$ with reduced carcass fat and increased carcass protein [3]. It has been considered that most of the $\mathrm{GH}$ effects are mediated by insulin-like growth factor-I (IGF-I). The effects of the administered GH may be mediated by the IGF-I in pigs. Plasma levels of IGF-I are influenced by the nutritional status of pigs [4] as well as dogs and cattle [5, 6].

Received: October 2, 1995

Accepted: February 22, 1996

Correspondence to: Dr. Akihito OZAWA, National Institute of Animal Industry, Tsukuba Norinkenkyu Danchi, P. O. Box 5, Ibaraki 305, Japan
However, there is little information so far indicating how the administered $\mathrm{GH}$ effects the endocrine status under the various nutritional conditions of pigs. It is also reported that the response of plasma IGF-I to administered GH is decreased or suppressed by reduced feed intake for 3 days in cattle [6] or fasting for 5 days in human [7]. How the response of $\mathrm{GH}$ is changed during the first three days in fasting is still not clear in pigs and other species.

In the present study, the effect of the GH administration on the plasma IGF-I concentrations in growing pigs was investigated under three levels of feedings. The plasma insulin, thyroid hormones, glucose, and non-esterified fatty acid (NEFA) concentrations were measured. We also investigated the responsiveness of IGF-I to exogenous GH dur- 
ing $72 \mathrm{~h}$ fasting.

\section{Materials and Methods}

\section{Animals and experimental designs}

Experiment 1: Effect of $\mathrm{GH}$ at various feeding levels

Four pigs (Large white, barrows, 108 days old, $49.9 \pm 1.0 \mathrm{~kg}$ body weight (BW) at the beginning of the experiments) were surgically fitted with jugular vein catheters and maintained at $20^{\circ} \mathrm{C}$ in an air-conditioned room. The pigs were fed at three feeding levels: (1) high level, (2) maintenance level, and (3) fasting level. At the high level, the pigs were fed 8,501 $\pm 46 \mathrm{kcal} /$ day and $357 \pm 1.9 \mathrm{~g} /$ day of digestive crude protein (DCP). At the maintenance level, the pigs were fed 2,104 $\pm 44 \mathrm{kcal} /$ day and $88 \pm 1.9 \mathrm{~g} /$ day of DCP. The amount of feeding was calculated according to the Japanese Feeding Standard for Swine [8]. The diet for fattening the pigs, which was formulated by our institute, was used throughout the experiments (TDN 70.1\%, DCP 12.7\%). These pigs were fed half the volume mentioned above at $0900 \mathrm{~h}$ and $1700 \mathrm{~h}$. In the fasting experiment, the pigs were fed at high levels until the last meal, which was given at $0900 \mathrm{~h}$ on day -2 .

Every day at $0900 \mathrm{~h}$ before feeding during the experiment, blood samples were taken through the catheter. At $1100 \mathrm{~h}$ on days 0,1 , and 2, $100 \mu \mathrm{g} / \mathrm{kg}$ BW of recombinant bovine GH (Eli Lilly Co.) dissolved in $10 \mathrm{ml}$ of carbonate buffer $(\mathrm{pH}=9.5)$ was subcutaneously injected. Blood samples on day 1 were taken at $-2,0,1,2,3,4,5,6,12$, and $24 \mathrm{~h}$ relative to the injection. The samples were placed in tubes containing heparin and were immediately chilled on ice until centrifugation. The plasma samples were stored at $-80^{\circ} \mathrm{C}$ prior to the hormone assays.

Experiment 2: Effect of GH under different durations of fasting

Four pigs (Landrase, barrows, 120 days old, 50.4 $\pm 0.7 \mathrm{~kg} \mathrm{BW}$ ) were surgically fitted with jugular vein catheters. The pigs were fed at the high level until feeding was stopped. The last meal was given at time 0 . At the times $2 \mathrm{~h}, 26 \mathrm{~h}$, and $50 \mathrm{~h}, 100$ $\mu \mathrm{g} / \mathrm{kg} \mathrm{BW}$ of the bovine GH or vehicle was subcutaneously injected and blood samples were taken at $-2,0,1,2,3,4,5,6,9,12,22$, and 24 h relative to the injection. The samples were treated as previously mentioned.

\section{Plasma hormone assays}

To determine the basal level of the plasma GH concentrations, a porcine $\mathrm{GH}(\mathrm{pGH})$ radioimmunoassay (RIA) was employed, which was described elsewhere [9]. Concentrations less than $1 \mathrm{ng} / \mathrm{ml}$ were calculated as $1 \mathrm{ng} / \mathrm{ml}$ in further analyses.

To determine the plasma GH concentrations after the GH injections, a bovine GH (bGH) RIA was employed, which was described previously [10].

The plasma IGF-I was extracted with acid ethanol, and its concentration was determined by RIA as previously described [11]. The plasma $\mathrm{T}_{3}$ and $\mathrm{T}_{4}$ were determined by RIA as previously mentioned [12]. The plasma insulin concentrations were determined with a specific RIA kit (Eiken Chemical Co.).

\section{Plasma metabolite assays}

The plasma glucose and NEFA concentrations were determined with specific assay kits (Glucose B-test Wako and NEFA-test Wako, respectively; Wako Pure Chemical Co.).

\section{Statistical analyses}

The statistical analyses were performed using the statistical software package, SAS (release 6.09.02, 1994, by SAS Institute). The means and standard error (SEM) of the hormone and metabolite concentrations were calculated using the means procedure of SAS and expressed as the mean \pm SEM. Data in experiment 1 were subjected to an analysis of variance (ANOVA) using the GLM procedure. The model included feeding level, day (or time), and animal as the main effects, as well as the interaction between the feeding level and day (or time). Tukey's studentized range test was employed to assess the hormone or metabolite levels between feeding levels. Then the data were sorted by feeding level and subjected to an ANOVA by every feeding level. The model included day (or time) and animal as the main effects. Dunnett's $t$ test was used to assess the hormone and metabolite levels between day 0 (or time 0 ) and other experimental points at one feeding level. In experiment 
2 , the paired $t$-test was used to assess the statistical significance of the concentrations between the control and GH injected animals.

\section{Results}

\section{Experiment 1: Effect of $\mathrm{GH}$ at various feeding levels}

The plasma IGF-I and pGH concentrations at $0900 \mathrm{~h}$ are shown in Fig. 1. The plasma IGF-I concentrations were elevated in the high level and maintenance fed animals. However, in the case of the fasting animals, the plasma IGF-I levels were not elevated. Plasma IGF-I levels of three groups were different each other. The plasma pGH concentrations were very low after day 1 in all groups. The plasma $T_{3}$ concentrations at $0900 \mathrm{~h}$ were significantly increased on the day 1-3. However, the plasma $\mathrm{T}_{4}$ concentrations were significantly de-

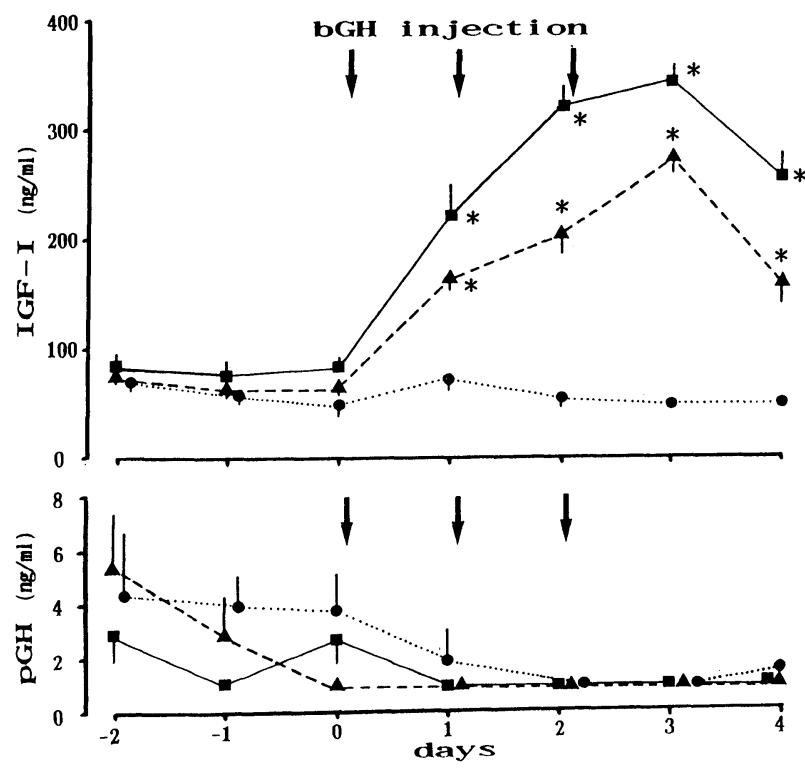

Fig. 1. Effect of GH injections on the plasma IGF-I (upper) and pGH (lower) concentrations at $0900 \mathrm{~h}$ in pigs fed at the high level $(\boldsymbol{\square})$, maintenance level $(\boldsymbol{\Delta})$, and fasting level (O). The bGH $(100 \mu \mathrm{g} / \mathrm{kg} \mathrm{BW})$ was subcutaneously injected at $1100 \mathrm{~h}$ on days 0,1 , and 2 . The asterisks indicate the statistical significance of the concentrations compared to pre-injection on day $0(P<0.05$, Dunnett's $t$-test $)$. Plasma IGF-I concentrations in animals at three feeding levels were different from each other (Tukey's studentized range test, $P<0.05)$. Each point with the vertical bar in the graph represents the mean $\pm S E M, n=4$. creased on the day 4 (Fig. 2). The bovine GH levels in the plasma were elevated within $2 \mathrm{~h}$ after the bGH injection and the higher $\mathrm{GH}$ levels were continued for at least $4 \mathrm{~h}$. The plasma bGH returned to the basal level within $24 \mathrm{~h}$ (data not shown). The changes in the plasma bGH levels after the bGH injection were similar in all of the feeding levels. The plasma glucose concentrations were increased in the animals fed at the high and maintenance levels after the GH injection (Fig. 3 upper). The plasma NEFA concentrations in fasting animals were significantly higher than those in the animals fed at the high and maintenance levels (Fig. 3 middle). The plasma NEFA concentrations were increased after the GH injection in maintenance fed and fasting animals. Plasma NEFA concentrations were not changed in the high level fed animals. Plasma insulin concentrations in the fasting animals were lower than those in the animals fed at the high and maintenance levels (Fig. 3
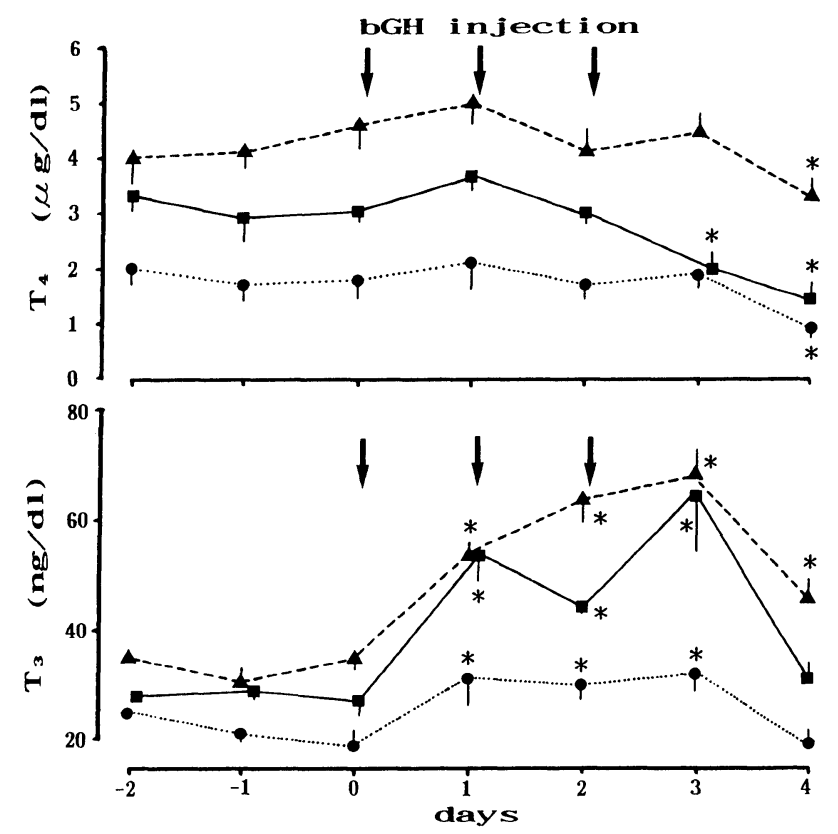

Fig. 2. Effect of $\mathrm{GH}$ injections on the plasma $\mathrm{T}_{4}$ (upper) and $\mathrm{T}_{3}$ (lower) concentrations at $0900 \mathrm{~h}$ in pigs fed at the high level $(\square)$, maintenance level $(\boldsymbol{\Delta})$, and fasting level (O). The bGH (100 $\mu \mathrm{g} / \mathrm{kg} \mathrm{BW})$ was subcutaneously injected at $1100 \mathrm{~h}$ on days 0,1 , and 2 . The asterisks indicate the statistical significance of the concentrations compared to pre-injection on day $0\left(P<0.05\right.$, Dunnett's $t$-test). Plasma $T_{4}$ and $T_{3}$ levels in animals at three feeding levels were different from each other (Tukey's studentized range test, $P<0.05)$. Each point with the vertical bar in the graph represents the mean $\pm S E M, n=4$. 
lower). Plasma insulin concentrations in the animals fed at the maintenance levels were decreased after the GH administration.

\section{Experiment 2: Effect of $\mathrm{GH}$ under different durations of fasting}

Figure 4 (upper) shows the plasma bGH concentration after the bGH injection during the fasting period. The plasma bGH increases were similar when the injections were performed at 2, 26, or 50 $\mathrm{h}$ after the last meal. Figure 4 (lower) shows the change in plasma IGF-I during the fasting period. Plasma IGF-I gradually decreased after the last meal. The GH injection administered $26 \mathrm{~h}$ or $50 \mathrm{~h}$ after the last meal still had the effect of increasing
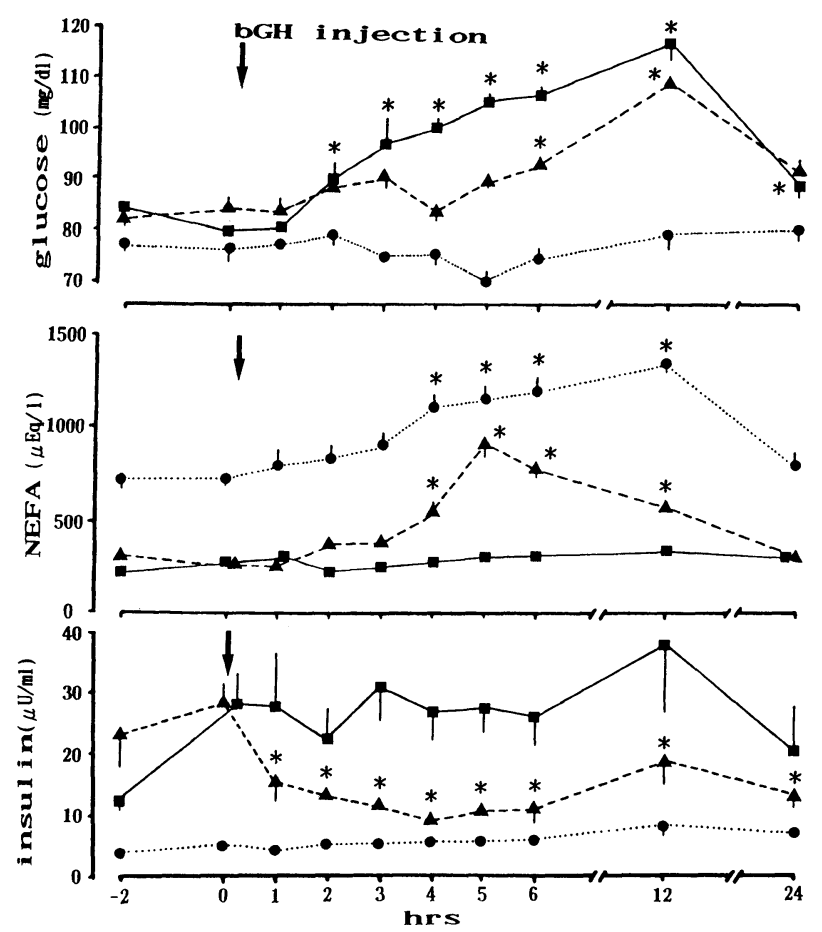

Fig. 3. The plasma glucose (upper), NEFA (middle), and insulin (lower) concentrations after the $\mathrm{GH}$ injection on day 1 in the pigs fed at the high level $(\square)$, maintenance level $(\boldsymbol{\Delta})$, and fasting level $(\boldsymbol{O})$. The bGH $(100 \mu \mathrm{g} / \mathrm{kg} \mathrm{BW})$ was subcutaneously injected at time 0 . The asterisks indicate the statistical significance of the concentrations compared to preinjection at time $0(P<0.05$, Dunnett's $t$-test). Plasma glucose, NEFA, and insulin concentrations in three feeding levels were different from each other (Tukey's studentized range test, $P<0.05$ ). Each point with the vertical bar in the graph represents the mean \pm SEM, $\mathrm{n}=4$. plasma IGF-I concentrations. In any case, plasma IGF-I concentrations were significantly increased $12 \mathrm{~h}$ after the bGH injection as compared to the control (vehicle injection).

\section{Discussion}

The plasma IGF-I concentrations were extremely increased in the high level fed animals, slightly increased in the maintenance fed animals, and not increased in the fasting animals in experiment 1 . The reduced responsiveness to the exogenous $\mathrm{GH}$ in the low energy intake or the protein-restricted conditions has been reported in several species $[6$, $7,13]$. However, as the plasma IGF-I concentrations in the control animals were decreasing over $72 \mathrm{~h}$, the responsiveness to the exogenous $\mathrm{GH}$ was not lost or extremely reduced even in the fasting

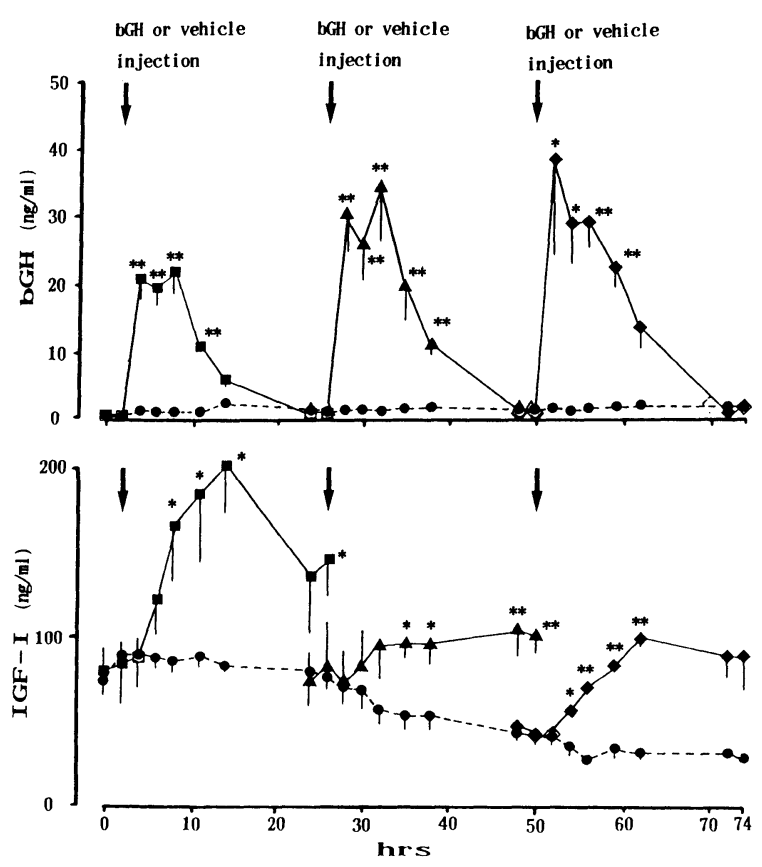

Fig. 4. Effect of $\mathrm{GH}$ injection on the plasma bGH (upper) and IGF-I (lower) concentrations in control pigs (vehicle injected:O) and bGH injected pigs (100 $\mu \mathrm{g} / \mathrm{kg} \mathrm{BW}, \boldsymbol{\square}$ at time $2 \mathrm{~h}, \boldsymbol{\Delta}$ at time $26 \mathrm{~h}$ and at time $50 \mathrm{~h}$ ) under the different durations of fasting. The last meal was given at time 0 . The asterisks indicate the statistical significance between the control and GH injected animals $\left({ }^{*}: P<0.05,{ }^{* *}: P<0.01\right.$, the Student's paired $t$-test). Each point with the vertical bar in the graph represents the mean \pm SEM, $n=4$. 
animals (Fig. 4). On the other hand, the repetitive GH injections increased plasma IGF-I concentrations, even though the plasma IGF-I concentrations had already been high when nutritional conditions were fair. It is reported that the repeated $\mathrm{GH}$ administrations were more effective in increasing plasma IGF-I in normal pigs than a single bolus administration [14].

The secretion of endogenous $\mathrm{GH}(\mathrm{pGH})$ seemed to be suppressed by the $\mathrm{GH}$ administration (Fig. 1 lower), because all the animals $(n=4)$ in experiment 1 had low pGH concentrations (less than $1 \mathrm{ng} / \mathrm{ml}$ ) after the GH administration, whilst 1 or 2 animals always had high pGH concentrations before GH administration. However, this suppression of $\mathrm{GH}$ secretion was not statistically significant because of the large individual variation in plasma $\mathrm{pGH}$ concentrations. And in experiment 1, only one sample was obtained from each animal on each experimental day. It was difficult to determine the GH secretion status in the animals by this sampling schedule, because $\mathrm{GH}$ is secreted in a pulsatile manner.

The plasma $T_{3}$ concentrations were increased after the $\mathrm{GH}$ injections (Fig. 2). The increase in $\mathrm{T}_{3}$ after $\mathrm{GH}$ administration was in agreement with a previous report in pig [15]. It is seemed that the increase in $T_{3}$ is not mediated at the level of the thyroid gland, because it was reported that the effects of thyrotropin stimulating hormone were not different between $\mathrm{GH}$-treated pigs and controls [16]. And it was reported that the activity of hepatic 5' monodeiodinase was increased after $\mathrm{GH}$ administration in chickens [17]. This enzyme converts $T_{4}$ to $T_{3}$. The increase in plasma $T_{3}$ after $G H$ injection in this study may reflect the $\mathrm{T}_{4}$ to $\mathrm{T}_{3}$ converting activity in peripheral tissue. And the increase in plasma $T_{3}$ in fasting pigs was smaller than that in high level or maintenance fed pigs, which may also reflect the change in deiodinase activity influenced by the nutritional status of the pigs.

The administration of the GH increased the plasma glucose concentrations in the high level and maintenance fed animals; however, the plasma glucose concentrations in the fasting animals were not increased (Fig. 3 upper). In contrast, the plasma NEFA concentrations were increased in the fasting and maintenance fed animals but not elevated in the high level fed animals (Fig. 3 middle). These data suggest that the glucose and NEFA utiliza- tion after the GH injection changed with the nutritional conditions of the animals.

It is well-known that GH has a diabetogenic effect. In this study, in the high level and maintenance fed animals, the plasma glucose concentrations were increased after $\mathrm{GH}$ injection as expected. Plasma glucose concentrations were the highest at $12 \mathrm{~h}$ after the $\mathrm{GH}$ injection. On the other hand, plasma $\mathrm{GH}$ concentrations were the highest at 2-6 h after the GH injection. Apparently this seems to be a discrepancy. However, according to a recent report, an increase in the plasma glucose concentrations was observed during IGF-I infusion into sheep [18]. At the same time, a decrease in the plasma insulin concentration was observed. A decrease in the plasma insulin concentration during an IGF-I infusion was also reported in human [19]. In this study, a decrease in the plasma insulin concentration was observed in the maintenance fed pigs (Fig. 3 lower). And despite the highest glucose concentration $12 \mathrm{~h}$ after GH injection, no significant increase in the plasma insulin concentration was observed in the high level or maintenance fed animals. According to these evidences, it is seemed that a direct effect of GH may increase the plasma glucose level at first, then an insufficient insulin secretion caused by an increase in plasma IGF-I may produce an additional increase in plasma glucose.

Plasma NEFA concentrations were increased in fasting and maintenance fed animals (Fig. 3 middle). It is reported that $\mathrm{GH}$ can alter the responsiveness of adipose tissue to other lipolytic hormones. GH treatment increased the response to a catecholamine challenge in lactating cows [20]. In this study, it was seemed that the fasting animals with low glucose concentrations might have high catecholamine concentrations. And low insulin and IGF-I concentrations in fasting animals also promoted lipolysis in adipose tissue. Under these conditions, GH treatment may have increased plasma NEFA concentrations in fasting animals. On the other hand, in maintenance fed animals, plasma insulin concentrations were decreased after the $\mathrm{GH}$ injection. This decrease in plasma insulin may have increased plasma NEFA.

In conclusion, the changes in plasma IGF-I, $\mathrm{T}_{3}$, glucose, and NEFA concentrations after the $\mathrm{GH}$ injection differed depending on the nutritional condition of the pigs. Although the plasma IGF-I concentrations did not increase in the fasting ani- 
mals, GH still had an effect in increasing or maintaining the plasma IGF-I concentrations, because plasma IGF-I was constantly decreasing in the control animals. These data clearly show that the effect of GH was modified by the nutritional condition of pigs.

\section{Acknowledgements}

The authors are grateful to Eli Lilly Co. for the generous gift of bovine $\mathrm{GH}$. The authors wish to thank Dr. T. Ishii, Dr. F. Ohtani, and Dr. T. Akita for their valuable assistance.

\section{References}

1. Chung CS, Etherton TD, Wiggins JP (1985) Stimulation of swine growth by porcine growth hormone. J Anim Sci 60: 118-130.

2. Etherton TD, Wiggins JP, Evock CM, Chung CS, Rebhun JF, Walton PE, Steele NC (1987) Stimulation of pig growth performance by porcine growth hormone: Determination of the dose-response relationship. J Anim Sci 64: 433-443.

3. Campbell RG, Steele NC, Caperna TJ, McMurtry JP, Solomon MB, Mitchell AD (1989) Effect of exogenous porcine growth hormone administration between 30 and 60 kilograms on the subsequent and overall performance of pigs grown to 90 kilograms. J Anim Sci 67: 1265-1271.

4. Dauncey MJ, Shakespear RA, Rudd BT, Ingram DL (1989) Variation in somatomedin-C/insulin-like growth factor-I associated with environmental temperature and nutrition. Horm Meta Res 22: 261-264.

5. Eigenmann JE, de Bruijne JJ, Froesch ER (1985) Insulin-like growth factor I and growth hormone in canine starvation. Acta Endocrinol 108: 161-166.

6. Ronge H, Blum J (1989) Insulin-like growth factor I responses to recombinant bovine growth hormone during feed restriction in heifers. Acta Endocrinol 120: 735-744.

7. Merimee TJ, Zapf J, Froesch ER (1982) Insulin-like growth factors in fed and fasted states. J Clin Endocrinol Metab 55: 999-1002.

8. Research Council Secretariat of Agriculture, Forestry, and Fisheries (1993) Japanese Feeding Standard for Swine. Ministry of Agriculture, Forestry and Fisheries, Tokyo (In Japanese).

9. Johke T, Hodate K, Ozawa A, Hodate Kyo, Kawabata A (1993) Effects of aging, thyrotropin releasing hormone and stress on plasma concentrations of growth hormone in the growing pigs. Bull Nat Inst Anim Ind 53: 15-22 (In Japanese).

10. Johke T (1978) Effects of TRH on circulating growth hormone, prolactin and triiodothyronine levels in the bovine. Endocrinol Japon 25: 19-26.

11. Ozawa A, Johke T, Hodate K (1994) Plasma insulin-like growth factor-I response to cold exposure in barrows. Endocr J 41: 725-730.
12. Hodate K, Kawabata A, Hodate Kyo, Johke T (1983) Changes of plasma levels of thyroxine and triiodothyronine after thyrotropin releasing hormone injection in swine. Bull Nat Inst Anim Ind 40: 15-22 (In Japanese).

13. Thissen JP, Triest S, Underwood LE, Maes M, Ketelslegers JM (1990) Divergent response of serum insulin-like growth factor-I and liver growth hormone $(\mathrm{GH})$ receptors to exogenous $\mathrm{GH}$ in protein-restricted rats. Endocrinology 126: 908-913.

14. Walton PE, Etherton TD (1989) Effect of porcine growth hormone and insulin-like growth factor-I (IGF-I) on immunoreactive IGF-binding protein concentration in pigs. J Endocrinol 120: 153-160.

15. Kirkwood RN, Thacker PA, Laarveld B (1989) The influence of growth hormone injections on the endocrine and metabolic status of gilts. Domest Anim Endocrinol 6: 167-176.

16. Kirkwood RN, Thacker PA, Laarveld B (1990) The influence of growth hormone treatment on thyroid function in swine. Can J Anim Sci 70: 991-995.

17. Kuhn ER, Verheyen G, Chiasson RB, Huts C, Huybrechts L Van den Steen P, Decuypere E (1987) Growth hormone stimulates the peripheral conversion of thyroxine into triiodothyronine by increasing the liver $5^{\prime}$ mono-deiodinase activity in the fasted and normal fed chicken. Horm Metab Res 19: 304308.

18. Cottam YH, Blair HT, Gallaher BW, Purchas RW, Breier BH, McCutcheon SN, Gluckman PD (1992) Body growth, carcass composition, and endocrine change in lambs chronically treated with recombinantly derived insulin-like growth factor-I. Endocrinology 130: 2924-2930.

19. Guler H-P, Schmid C, Zapf J, Froesch R (1989) Effects of recombinant insulin-like growth factor-I on insulin secretion and renal function in normal human subjects. Proc Natl Acad Sci USA 86: 2868-2872.

20. McCutchen SN, Bauman DE (1986) Effect of chronic growth hormone treatment on responses to epinephrine and thyrotropin-releasing hormone in lactating cows. J Dairy Sci 69: 44-51. 